\title{
KANGAROO CARE STABILIZES PRETERM INFANT PHYSIOLOGY \\ AS MEASURED BY HEART RATE VARIABILITY \\ - A MATTRESS SIMULATING ASPECTS OF KANGAROO CARE DOES NOT
}

\author{
D. Kommers, R. Joshi, C. van Pul, L. Feijs, G. Oei, S. Bambang Oetomo, P. Andriessen \\ Máxima Medical Centre, Veldhoven, in collaboration with Eindhoven University of Technology
}

\section{Background:}

Numerous positive effects of Kangaroo care (KC) have been reported. However, the duration that parents can spend kangarooing is often limited.

The purpose of our study is to investigate whether a mattress developed to mimic breathing motion and the sounds of heartbeats (BabyBe $\mathrm{GMBH} \circledast$, Stuttgart, Germany) can simulate aspects of $\mathrm{KC}$ in preterm infants as measured by features of beat-to-beat heart rate variability (HRV).
Methods: A within-subject design in which every routine $\mathrm{KC}$ session was followed by a BabyBe (BB) session, with a washout period of at least two hours in between. Nurses annotated start and end times of $\mathrm{KC}$ and $\mathrm{BB}$ sessions. Data from the pre- $\mathrm{KC}, \mathrm{KC}$, post-KC, pre-BB, $B B$ and post-BB periods were retrieved from the patient monitor via a data warehouse. Five features of HRV were used to compare the effect of KC and the mattress. One of these features, the standard deviation of decelerations (SDDec) specifically captures the contribution of transient heart rate decelerations to HRV, a measure of regulatory instability of the autonomic nervous system.
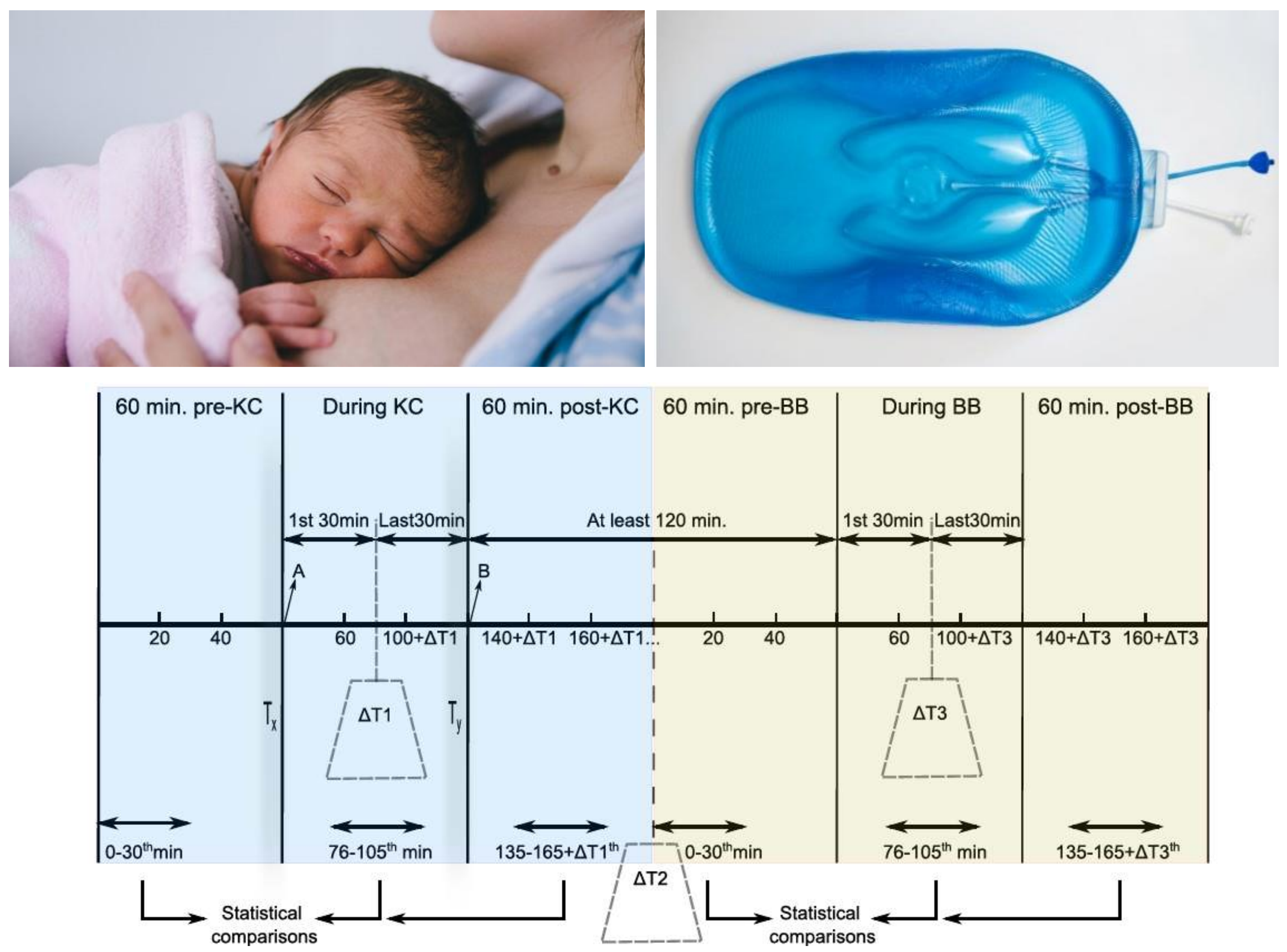

Results and conclusion:
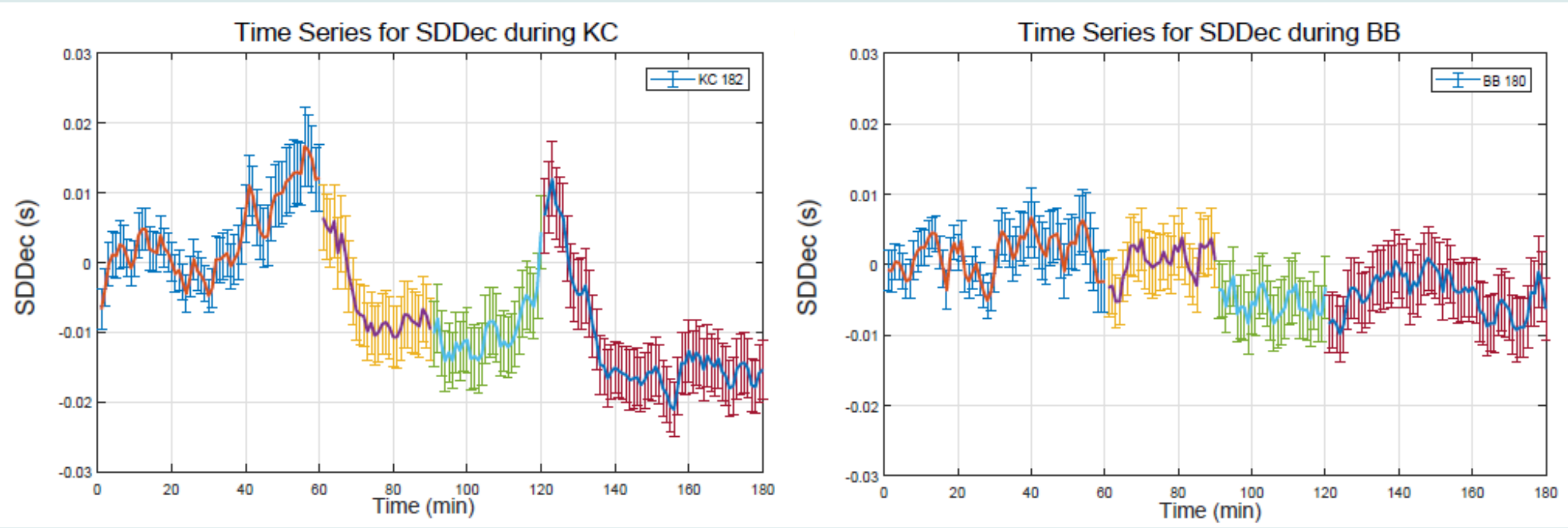

In total, $182 \mathrm{KC}$ and 180 BabyBe sessions were analyzed in 20 preterm infants. Autonomic regulation stabilized during KC as reflected by a reduction in SDDec. After KC, this effect remained ( $p \leq 0.01)$. The mattress did not affect SDDec significantly. 